\title{
Surgical resection or radiofrequency ablation in the management of hepatocellular carcinoma: single center experience
}

\author{
Wael Mansy ${ }^{1}$, Morsi Mohammed ${ }^{1}$, Sameh Saber ${ }^{2}$ \\ ${ }^{1}$ Department of General Surgery, Faculty of Medicine, Zagazig University, Zagazig 44519, Egypt \\ ${ }^{2}$ Department of Radiology, Faculty of Medicine, Zagazig University, Zagazig 44519, Egypt
}

\begin{abstract}
Aim: The aim of this study is to prove or disprove the superiority of surgical resections over radiofrequency ablation (RFA) with respect to efficacy and safety. Methods: The study was conducted in Zagazig University Hospitals, which included 40 patients with hepatocellular carcinoma (HCC) during the period from November 2011 to December 2014, using either liver resection or RFA. Results: Hepatic resection was done in 20 patients (13 males, 7 females). Interventional RFA was done in 20 patients (12 males, 8 females). There was no in-hospital mortality after resection. One- and two-year survival rates were $85 \%$ and $70 \%$ respectively. There was no in-hospital mortality after RFA. One- and two-year survival rates were $80 \%$ and $65 \%$ respectively. Conclusion: Surgical resection is preferred over RFA in HCC-liver cirrhosis Child A patients with tumor sizes $\geq 3 \mathrm{~cm}$. HCC-liver cirrhosis Child A patients with masses $<3 \mathrm{~cm}$ have almost the same results with both surgery and RFA. But in special cases such as central position lesions, RFA is preferred over resection. Also the decision for management may be changed according to patients well. Surgical resection 1- and 2-year survival rates were better than those treated with RFA.
\end{abstract}

Key words: Hepatocellular carcinoma; liver resection; radiofrequency ablation

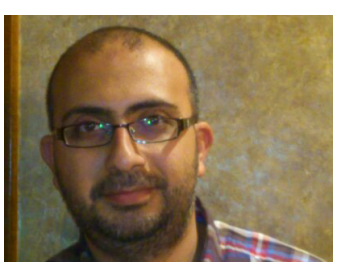

\section{Address for correspondence:}

Dr. Wael Mansy, Department of General Surgery, Faculty of Medicine, Zagazig University,

Zagazig 44519, Egypt. E-mail: drwaelmansy@hotmail.com

Received: 27-06-2015, Accepted: 26-10-2015

\section{INTRODUCTION}

Hepatic resection (HR) forms part of the conventional treatment for patients with hepatocellular carcinoma (HCC) ${ }^{[1]}$ Size, site, number of tumors, vascular and extrahepatic involvement as well as liver function respresent some aspects that prompt surgical resection difficulties. Accordingly, the majority of primary liver cancers are not suitable for curative resection at the time of diagnosis..$^{[2,3]}$

\begin{tabular}{|l|c|}
\hline \multicolumn{3}{|c|}{ Access this article online } \\
\hline \multirow{2}{*}{ Website: } & Quick Response Code \\
\cline { 2 - 2 } http://hrjournal.net & \\
\hline &
\end{tabular}

Radiofrequency ablation (RFA) is recommended for HCC nodules with a maximum diameter of $3 \mathrm{~cm}$ in patients with no more than three tumors that are contraindicated for surgery. ${ }^{[4]}$

\section{METHODS}

The patients were diagnosed through history taking,

This is an open access article distributed under the terms of the Creative Commons Attribution-NonCommercial-ShareAlike 3.0 License, which allows others to remix, tweak, and build upon the work non-commercially, as long as the author is credited and the new creations are licensed under the identical terms.

For reprints contact: service@oaepublish.com

How to cite this article: Mansy W, Mohammed M, Saber S. Surgical resection or radiofrequency ablation in the management of hepatocellular carcinoma: single center experience. Hepatoma Res 2016;2:92-7. 
complete physical examination, laboratory investigations [complete blood count, coagulation profile, liver function test, kidney function test and alpha-fetoprotein (AFP)], and radiological investigations [abdominal ultrasonography and triphasic computerized tomography (CT)]. They were categorized into two groups. Group A: 20 patients for whom $\mathrm{HR}$ was done (according to the size, site and number of tumors); Group B: 20 patients for whom RFA was done using percutaneous ultrasonography.

\section{Inclusion criteria}

Patients with or without liver cirrhosis. Patients with Child A and B (Child-Pugh classification). Patients with or without hepatitis $B$ or $C$ infection. Patients who have HCCs diagnosed by triphasic CT \pm elevated AFP.

\section{Exclusion criteria}

Patients with Child C liver disease. Patients with HCC tumors outside of the Milan criteria and are not candidates for RFA (central lesion near common bile duct, lesion adherent to bowel loop, lesion not accessible and lesion exophytic). Patients with HCC metastasis.

\section{Follow-up}

The patients in both groups were followed up for 2 years and we then compared the two groups with regards to operative mortality, morbidity, hospital stay, and 1- and 2-year overall states. The results and the recurrence were measured by the changes in AFP levels, abdominal ultrasound, and triphasic CT scan after 1 month then every 3 months in the 1 st year and subsequently every 6 months for the 2nd year.

\section{Surgical resection}

Group A: From November 2011 to December 2014, 20 consecutive patients with HCC (13 males, 7 females; average age: 53.4 years; range: 45-62 years) underwent HR at Zagazig University Hospitals, Surgical Department. All resections were considered radical (tumor-free resection margins confirmed by pathology) [Figures 1-3].

Patients prepared preoperatively by using central line and epidural catheters a day before surgery. Packed red blood cells and fresh frozen plasma were prepared according to patient labs.

Incision used was usually L-shaped, rarely we needed to conduct bilateral subcostal with midline incisions. Before we started, we usually assessed the operability via feeling of the mass, searching for other masses and searching for enlarged lymph nodes. Complete mobilization was the first step. Identification of the hilar structures is the second step. Even if we were not going to do typical hepatectomies and this for control of possible bleeding. During operation

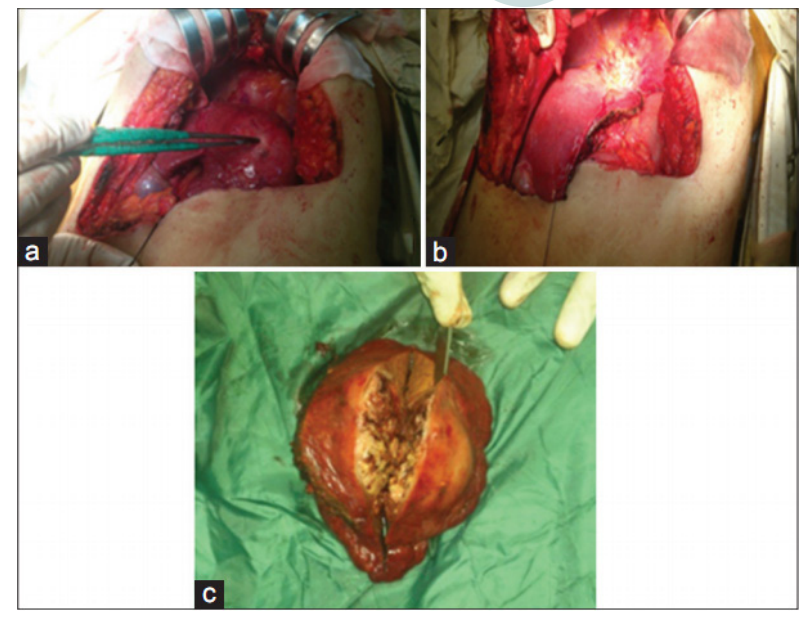

Figure 1: Right liver lobe hepatocellular carcinoma resection. (a) Intra operative identification of the mass; (b) liver bed after resection of the mass; (c) opening of the mass after excision

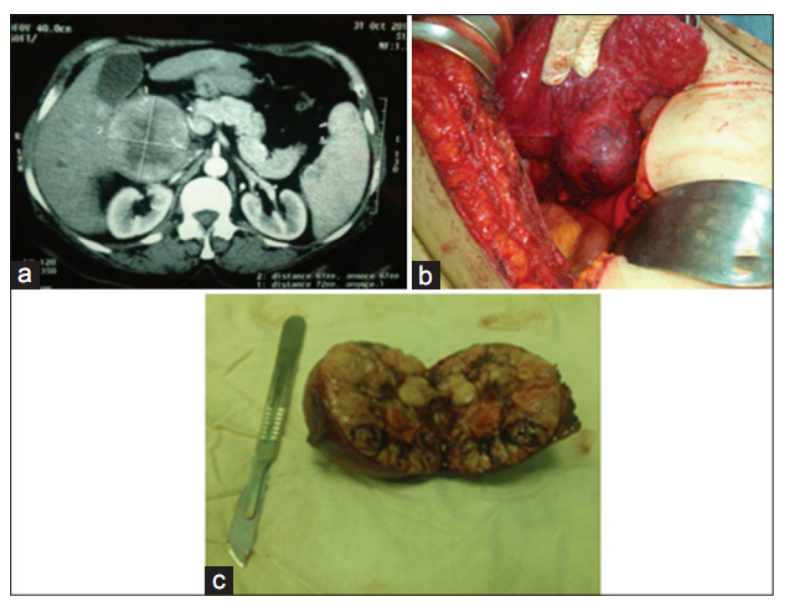

Figure 2: Caudate lobe liver resection. (a) Triphasic computerized tomography identification of caudate lobe mass; (b) intraoperative identification of caudate lobe mass; (c) opening of the mass after excision

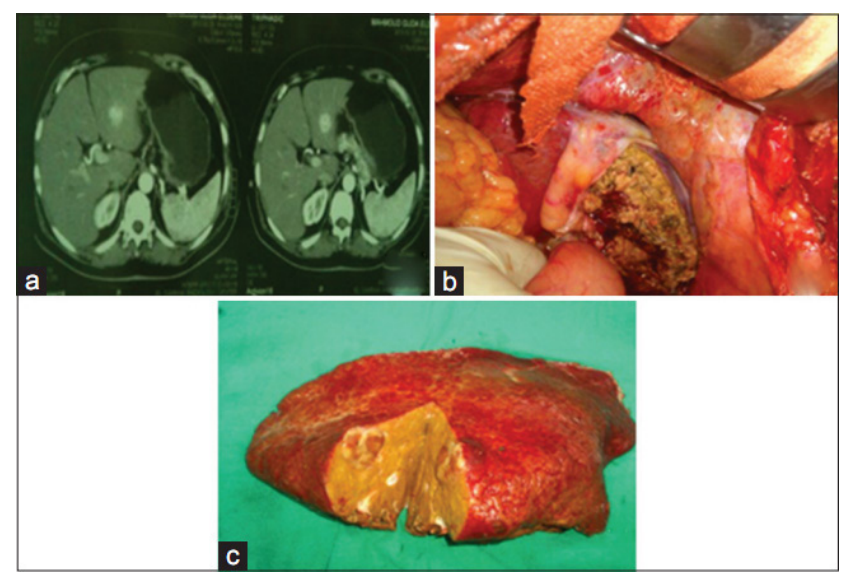

Figure 3: Left liver lobe hepatocellular carcinoma resection. (a) Triphasic computerized tomography identification of left lobe mass (left lateral segment); (b) liver bed after resection of the mass; (c) opening of the mass after excision

we used a harmonic scalpel for parenchyma dissection. We were ready to conduct the Pringle maneuver, but only used it when needed. Meticulous haemostasis was maintained as usual and bile leakage was avoided. Tube drains were only inserted in susceptible patients. 


\section{Post-operative management}

Five patients were transferred to the Intensive Care Unit and were under observation until patients became stable. A naso-gasteric tube was left for $24 \mathrm{~h}$. Patients started oral fluids when intestinal sounds became audible, and gradually returned to a normal diet. Ambulance was started as early as possible. Drains were removed when below $100 \mathrm{~mL}$ (usually the 4th day). Hospital stay keep as short as possible to avoid hospital acquired infection, ranging from 5 days to 7 days.

In the same period, 20 consecutive patients with HCC (12 males, 8 females; average age: 54.3 years; range: 48-66 years) underwent percutaneous RFA at Zagazig University Hospitals, Interventional Radiology Department [Figure 4].

Thirteen of them were treated using the Radionics cool tip needle ( 4 ablated by the single probe and 8 by the cluster probe). Seven patients were treated using the Rita needle with expandable hooks. Fifteen patients were treated with a single electrode insertion, 4 with double insertions and in one case, by three insertions. Only 1 patient received a second session of RFA due to a residual tumor detected by the 1-month follow-up triphasic CT study.

Local anesthesia was performed on the entry site of the skin to the liver capsule along the needle track with $10 \mathrm{~mL}$ of $2 \%$ xylocaine. Most of the patients undergoing RFA were treated under general intravenous (IV) anesthesia.

The objective in treating the tumors was to ablate the entire tumor and an at least $1 \mathrm{~cm}$ tumor-free margin
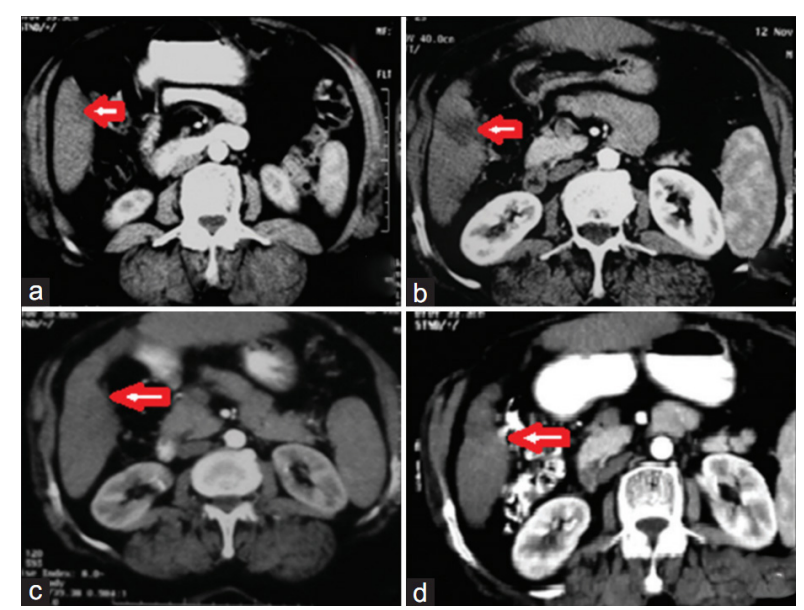

Figure 4: (a) Arterial contrast enhanced triphasic computerized tomography shows right lobe (segment 6) hepatocellular carcinoma about $16 \mathrm{~mm} \times 14$ $\mathrm{mm}$; (b) arterial phase 1 month after RFA; (c) arterial phase 3 months after RFA; (d) arterial phase 9 months after RFA. In b, c and d, no enhancement of the ablated right lobe. Significant decrease in mass size is noted. RFA: radiofrequency ablation of normal liver. The deepest ablations were performed before the superficial ones to minimize the possibility of micro bubbles that might obscure visualization of the deepest portions of the tumor and thus prevent complete ablation. In our cases, we ablated the tract before removal of the needle.

\section{Post-ablation care}

IV antiemetic was given. Strong IV analgesics were given to control pain. All patients were observed clinically for 2-3 $\mathrm{h}$ in the Radiology Department to detect any acute complications (like bleeding, shock and injury to other organs) and to start IV fluid. Prophylactic antibiotics were started and continued for 3 days.

\section{RESULTS}

\section{Sociodemographic characteristics of patients}

We compared tumor characteristics in the two different treatment groups (Child-Pugh score, tumor number, tumor diameter and AFP levels), as shown in Table 1.

\section{Group A: Resection}

A total of 20 consecutive patients with HCC (13 males, 7 females; average age: 53.4 years; range: $45-62$ years) underwent HR. The etiology of the patients' underlying liver disease were characterized by 20 patients with chronic hepatitis (hepatitis $B$ : 3 ; hepatitis $C: 14$; hepatitis B + C: 3). On the other hand, 17 had Child A and 3 had Child B, according to the Child-Pugh scoring system.

\section{Group B: Radiofrequency ablation}

A total of 20 consecutive patients with HCC (12 males, 8 females; average age: 54.3 years; range: 48-66 years) underwent RFA interventional in the Radiology Department. The etiology of the patients' underlying liver disease was characterized by 20 patients with chronic hepatitis (hepatitis B: 4 ; hepatitis $C: 14$; hepatitis B + C: 2). Of these patients, 12 had Child A and 8 Child B.

Table 1: Tumors characteristics in the two different treatment groups

\begin{tabular}{lcc}
\hline Underlying cirrhosis & $\begin{array}{c}\text { Group A } \\
\text { HR }(n=20)(\%)\end{array}$ & $\begin{array}{c}\text { Group B B } \\
\text { RFA } n=20)(\%)\end{array}$ \\
\hline Child-Pugh score & $17(85)$ & $12(60)$ \\
A & $3(15)$ & $8(40)$ \\
B & $18(90)$ & $13(65)$ \\
Number of tumors & $2(10)$ & $7(35)$ \\
$\quad$ Single & & \\
$\quad$ Multinodular & $5(25)$ & $4(20)$ \\
Tumor diameter & $15(75)$ & $16(80)$ \\
maximum $7.5 \mathrm{~cm}$ & $3(15)$ & $2(10)$ \\
$\leq 3 \mathrm{~cm}$ & $17(85)$ & $18(90)$ \\
$\quad 3 \mathrm{~cm}$ & & \\
AFP levels $(\mathrm{ng} / \mathrm{mL})$ & & \\
$\leq 20$ & &
\end{tabular}

RFA: radiofrequency ablation; AFP: alpha-fetoprotein; HR: hepatic resection 


\section{Treatment mortality and morbidity}

We found the difference in overall survival in the two different treatment groups regarding child type as shown in Table 2.

\section{Group A: Resection}

There was no operative mortality (within 30 days of surgery) after resection; mean hospital stay was 6 days. One- and two-year survivals were $85 \%$ (17) and 70\% (14) respectively.

Post-resection complications varied greatly. Wound infection (seroma) occured in 4 patients and were managed conser vatively via repeated dressing and antibiotic administration according to the culture obtained from the wound. Incisional hernia occured in 2 patients. Hernioplasty was performed in one of them while the other one refused. Chest complications were the most common complications, big incision and severe pain limits respiration, leading to retained secretions and chest infections. Chest complications occured in 8 patients. Ascitis occured in 3 patients and were managed medically. One patient developed recurrence after 18 months (this patient was managed by RFA but was excluded from our results, as RFA was done after finishing the study).

\section{Group B: Percutaneous radiofrequency ablation}

There was no in-hospital mortality after RFA; the mean hospital stay ranged from $4 \mathrm{~h}$ to $24 \mathrm{~h}$ with a mean of $7 \mathrm{~h}$. One- and two-year survival was respectively, $80 \%$ (16) and 65\% (13).

Pain after procedures was present in all patients (mild to moderate pain presented in 16 patients which was managed using analgesia. Severe pain presented in 4 patients and was managed using sedation). Pain lasted for 24-72 $\mathrm{h}$ in most patients. Delayed pain occurred in 2 patients lasting for 1 week. This was attributed to the proximity of the ablated lesions to the diaphragm. Pain occurred either isolated or as a part of the post-ablation syndrome that occurred in 12 patients with flu-like manifestations including low-grade fever, pain, malaise, myalgia, nausea, and vomiting.

Table 2: Overall survival by patient and child type in the two different treatment groups

\begin{tabular}{lcc}
\hline & 1 year $(\%)$ & 2 years (\%) \\
\hline Total patients & $17(85)$ & $14(70)$ \\
HR $(n=20)$ & $16(80)$ & $13(65)$ \\
RFA $(n=20)$ & $15(75)$ & $13(65)$ \\
Child A & $10(50)$ & $9(45)$ \\
HR $(n=17)$ & $2(10)$ & $1(0.5)$ \\
RFA $(n=12)$ & $6(30)$ & $4(20)$ \\
Child B & & \\
HR $(n=3)$ & RFA $(n=8)$ &
\end{tabular}

RFA: radiofrequency ablation; HR: hepatic resection
One case developed a new lesion detected 4 months post-procedure at the follow-up triphasic CT study managed by a second session.

Cholecystitis developed in 1 patient with a segment 5 nodule adjacent to the gall bladder wall. Bile duct injury developed in another patient 1 month post-procedure.

\section{DISCUSSION}

HCC accounts for more than $90 \%$ of primary liver cancer, the third most common cause of cancer-related death. It is the fifth most prevalent cancer in men and the seventh in women. ${ }^{[5,6]}$ The prognosis for untreated HCC is generally poor. Curative treatment consists of surgical resection, RFA, and liver transplantation. ${ }^{[7]}$

Management of cirrhotic HCC involves several specialties. ${ }^{[8]}$ To correctly select candidates for resection, it is essential to consider not only the tumor characteristics, but also the accurate estimate of liver function with the aid of imaging. The risk of incorrect staging of associated cirrhosis may result in post-operative liver failure, followed by chronic decompensated cirrhosis. ${ }^{[9]}$

The high mortality and morbidity associated with chronic liver disease limits liver resection in cirrhotic patients. ${ }^{[10]}$ Liver transplantation is the choice of treatment, with the best results in terms of long-term survival, but this option is feasible in a small number of patients because of the shortage of donors. ${ }^{[1]}$ However, current progresses in liver resection techniques and in post-operative followup have improved the resection results in terms of operative risk and long-term survival. ${ }^{[9,12]}$

Indications for resection depend on the size, number and location of lesions as well as the estimation of remnant liver volume (RLV). The best candidates are patients with a single peripheral lesion, which permits the preservation of more than $50 \%$ of RLV. ${ }^{[13]}$

Tumor location is an essential assessment parameter. With regard to peripheral lesions, no matter how bulky the mass is, resection may be performed with a curative intent and anatomically, without compromising a large parenchymal volume. ${ }^{[14]}$ In contrast, a small central lesion $(<3 \mathrm{~cm})$ may require the sacrifice of a significantly great parenchymal volume, with risk of post-operative liver failure, so RFA is preferable if possible. ${ }^{[15]}$

Surgical resection of HCC remains the gold standard. Unfortunately, its usefulness has been limited by many factors, including tumor multiplicity and poor hepatic reserve to tolerate surgery. Other techniques 
(e.g. percutaneous ethanol injection, microwave, RFA, and brachytherapy) may be effective and feasible in the treatment of HCC patients who are not suitable for resection. ${ }^{[16]}$ Among these, RFA may be beneficial to more patients than the others because of its large coagulated necrosis, fewer treatment sessions, and higher survival rates. ${ }^{[17-20]}$ Rare studies have evaluated the results of treatment with RFA, by comparing it to liver resection. $^{[21-23]}$

There was no in-hospital mortality after resection. Oneand two-year survivals were $85 \%$ and $70 \%$ respectively in our series. There was no in-hospital mortality after RFA. One- and two-year survival was $80 \%$ and $65 \%$, respectively. This finding agreed with Parisi et al. ${ }^{[16]}$ who concluded that surgical resection improved the overall survival and recurrence-free survival in comparison with RFA.

Our results regarding masses $<3 \mathrm{~cm}$ matched with other results of Nishikawa et al. ${ }^{[24]}$ who found that in patients with HCCs $<3 \mathrm{~cm}$, there was no significant difference between the two treatment groups in terms of overall survival. They concluded that RFA was as effective as resection in the treatment of single and small HCC, and was less invasive than surgery. Chen et al. ${ }^{[25]}$ suggests that RFA and surgery have similar results in terms of overall survival and RFS for single HCCs $<5 \mathrm{~cm}$. Abu-Hilal et al. ${ }^{[21]}$ showed that RFA should be considered as an acceptable alternative when surgery was not possible in small unifocal HCCs. Therefore, RFA could be the first choice of treatment for single and small HCC.

However, regarding masses more than $3 \mathrm{~cm}$, our results agree with Huang et al. ${ }^{[22]}$ who reported that in treating Child-Pugh A cirrhotic patients with a solitary HCC larger than $3 \mathrm{~cm}$ but $<5 \mathrm{~cm}$, or with two or three lesions each $<5 \mathrm{~cm}$, surgical resection provided a better survival than RFA.

RFA has some advantages compared with resection such as: Being less invasive, having a relatively rapid recovery period, and short hospital stay. But it also has shortcomings, such as more frequent local recurrence after treatment than resection. ${ }^{[26,27]}$

Furthermore, the resection group indicated higher incidences of complications compared with RFA. In addition, resection has weaknesses such as a longer hospital stay and a longer recovery period after operation. Our finding was in agreement with the study of Park et al. ${ }^{[28]}$ and Bruix et al. ${ }^{[29]}$

The study is based on a limited number of patients, however, our number are near other studies. ${ }^{[30,31]}$
Follow-ups were extremely difficult. Usually, when the patient feels improvement; he/she stops visiting our outpatient clinic for follow-ups.

In conclusion, surgical resection is preferred over RFA for HCC-liver cirrhosis Child A patients with tumor sizes $\geq 3 \mathrm{~cm}$. HCC-liver cirrhosis Child A patients with masses $<3 \mathrm{~cm}$ have almost the same results as both surgery and RFA. But in special cases such as central position lesions, RFA is preferred over resection. Also the decision for management may be changed according to patients well. Surgical resection 1- and 2-year survival rates were better than those treated with RFA.

\section{Financial support and sponsorship Nil.}

\section{Conflicts of interest}

There are no conflicts of interest.

\section{REFERENCES}

1. Cho YK, Kim JK, Kim WT, Chung JW. Hepatic resection versus radiofrequency ablation for very early stage hepatocellular carcinoma: a Markov model analysis. Hepatology 2010;51:1284-90.

2. Lee WS, Yun SH, Chun HK, Lee WK, Kim SJ, Choi SH, Heo JS, Joh JW, Choi D, Kim SH, Rhim H, Lim HK. Clinical outcomes of hepatic resection and radiofrequency ablation in patients with solitary colorectal liver metastasis. J Clin Gastroenterol 2008;42:945-9.

3. Mulier S, Ruers T, Jamart J, Michel L, Marchal G, Ni Y. Radiofrequency ablation versus resection for resectable colorectal liver metastases: time for a randomized trial? An update. Dig Surg 2008;25:445-60.

4. Tanaka S, Shimada M, Shirabe K, Taketomi A, Maehara S, Tsujita E, Ito S, Kitagawa D, Maehara Y. Surgical radiofrequency ablation for treatment of hepatocellular carcinoma: an endoscopic or open approach. Hepatogastroenterology 2009;56:1169-73.

5. Livraghi T, Mäkisalo H, Line PD. Treatment options in hepatocellular carcinoma today. Scand J Surg 2011;100:22-9.

6. El-Serag HB. Epidemiology of viral hepatitis and hepatocellular carcinoma. Gastroenterology 2012;142:1264-73.e1.

7. de Lope CR, Tremosini S, Forner A, Reig M, Bruix J. Management of HCC. J Hepatol 2012;56 Suppl 1:S75-87.

8. Guy J, Kelley RK, Roberts J, Kerlan R, Yao F, Terrault N. Multidisciplinary management of hepatocellular carcinoma. Clin Gastroenterol Hepatol 2012;10:354-62.

9. Kishi Y, Hasegawa K, Sugawara Y, Kokudo N. Hepatocellular carcinoma: current management and future development-improved outcomes with surgical resection. Int J Hepatol 2011;2011:728103.

10. Bilimoria MM, Lauwers GY, Doherty DA, Nagorney DM, Belghiti J, Do KA, Regimbeau JM, Ellis LM, Curley SA, Ikai I, Yamaoka Y; International Cooperative Study Group on Hepatocellular Carcinoma. Underlying liver disease, not tumor factors, predicts long-term survival after resection of hepatocellular carcinoma. Arch Surg 2001;136:528-35.

11. Hasegawa K, Kokudo N, Makuuchi M. Surgical management of hepatocellular carcinoma. Liver resection and liver transplantation. Saudi Med J 2007;28:1171-9.

12. Yang JM. Recent advances and controversies in surgical management of hepatocellular carcinoma. Zhongguo Yi Xue Ke Xue Yuan Xue Bao 2008;30:378-80. (in Chinese)

13. Bryant R, Laurent A, Tayar C, van Nhieu JT, Luciani A, Cherqui D. Liver resection for hepatocellular carcinoma. Surg Oncol Clin N Am 2008; 17:607-33, ix.

14. Xu G, Zhang JH, Cheng GF, Cai Y, Miao Y. Meta-analysis of surgical 
resection and radiofrequency ablation for early hepatocellular carcinoma. World J Surg Oncol 2012;10:163.

15. Park Y, Choi D, Lim HK, Rhim H, Kim YS, Kim SH, Lee WJ. Growth rate of new hepatocellular carcinoma after percutaneous radiofrequency ablation: evaluation with multiphase CT. AJR Am J Roentgenol 2008;191:215-20.

16. Parisi A, Desiderio J, Trastulli S, Castellani E, Pasquale R, Cirocchi $\mathrm{R}$, Boselli C, Noya G. Liver resection versus radiofrequency ablation in the treatment of cirrhotic patients with hepatocellular carcinoma. Hepatobiliary Pancreat Dis Int 2013;12:270-7.

17. Shibata T, Iimuro Y, Yamamoto Y, Maetani Y, Ametani F, Itoh K, Konishi J. Small hepatocellular carcinoma: comparison of radiofrequency ablation and percutaneous microwave coagulation therapy. Radiology 2002;223:331-7.

18. Iwata K, Sohda T, Nishizawa S, Nakane H, Yoshikane M, Koyama Y, Morihara D, Takeyama Y, Uehara Y, Kitamura Y, Irie M, Syakadou S, Yokoyama M, Kamimura S, Watanabe H, Sakisaka S. Postoperative recurrence in hepatocellular carcinoma: comparison between percutaneous ethanol injection and radiofrequency ablation. Hepatol Res 2006;36:143-8.

19. Seror O, N'Kontchou G, Tin Tin Htar M, Durand-Zaleski I, Trinchet JC, Sellier N, Beaugrand M. Ethanol versus radiofrequency ablation for the treatment of small hepatocellular carcinoma in patients with cirrhosis: a retrospective study of efficacy and cost. Gastroenterol Clin Biol 2006;30:1265-73.

20. Kong W, Zhang W, Qiu Y, Zhou T, Bin H. Prospective comparative study of cool-tip radiofrequency ablation and surgical resection for hepatocellular carcinoma. Chin Ger J Clin Oncol 2011;10:399-405.

21. Abu-Hilal M, Primrose JN, Casaril A, McPhail MJ, Pearce NW, Nicoli N Surgical resection versus radiofrequency ablation in the treatment of small unifocal hepatocellular carcinoma. J Gastrointest Surg 2008;12:1521-6.

22. Huang J, Hernandez-Alejandro R, Croome KP, Yan L, Wu H, Chen Z, Prasoon P, Zeng Y. Radiofrequency ablation versus surgical resection for hepatocellular carcinoma in child's A cirrhotics: a retrospective study of 1061 cases. $J$ Gastrointest Surg 2011;15:311-20.

23. Himoto T, Kurokohchi K, Watanabe S, Massaki T. Recent advances in radiofrequency ablation for the management of hepatocellular carcinoma. Hepat Mon 2012;12:e5945.

24. Nishikawa H, Inuzuka T, Takeda H, Nakajima J, Matsuda F, Sakamoto A, Henmi S, Hatamaru K, Ishikawa T, Saito S, Nasu A, Kita R, Kimura T, Arimoto A, Osaki Y. Comparison of percutaneous radiofrequency thermal ablation and surgical resection for small hepatocellular carcinoma. BMC Gastroenterol 2011;11:143.

25. Chen MS, Li JQ, Zheng Y, Guo RP, Liang HH, Zhang YQ, Lin XJ, Lau WY. A prospective randomized trial comparing percutaneous local ablative therapy and partial hepatectomy for small hepatocellular carcinoma. Ann Surg 2006;243:321-8.

26. Sutherland LM, Williams JA, Padbury RT, Gotley DC, Stokes B, Maddern GJ. Radiofrequency ablation of liver tumors: a systematic review. Arch Surg 2006;141:181-90.

27. Mulier S, Ni Y, Jamart J, Ruers T, Marchal G, Michel L. Local recurrence after hepatic radiofrequency coagulation: multivariate meta-analysis and review of contributing factors. Ann Surg 2005;242:158-71.

28. Park EK, Kim HJ, Kim CY, Hur YH, Koh YS, Kim JC, Kim HJ, Kim JW, Cho CK. A comparison between surgical resection and radiofrequency ablation in the treatment of hepatocellular carcinoma. Ann Surg Treat Res 2014;87:72-80.

29. Bruix J, Sherman M; American Association for the Study of Liver Diseases. Management of hepatocellular carcinoma: an update. Hepatology 2011;53:1020-2.

30. Feng K, Yan J, Li X, Xia F, Ma K, Wang S, Bie P, Dong J. A randomized controlled trial of radiofrequency ablation and surgical resection in the treatment of small hepatocellular carcinoma. J Hepatol 2012;57:794-802.

31. Liu J, Qian LX. Therapeutic efficacy comparison of radiofrequency ablation in hepatocellular carcinoma and metastatic liver cancer. Exp Ther Med 2014;7:897-900. 